\title{
Otimização dos parâmetros físicos de pães tipo forma incorporados de açaí e quitosana utilizando a metodologia de superfície de resposta
}

\author{
R. A. ZAMBELLI ${ }^{1}$, M. M. N. ARAÚJO'1, L. I. F. PINTO' ${ }^{1}$, G. K. PINHEIRO ${ }^{1}$, D. L. \\ BRASIL ${ }^{1}$, E. R. PONTES ${ }^{1}$ e D. F. PONTES ${ }^{1}$. \\ ${ }^{1}$ Universidade Federal do Ceará, Departamento de Tecnologia de Alimentos. \\ E-mail para contato: Zambelli@alu.ufc.br
}

\begin{abstract}
RESUMO - O trabalho teve como objetivo utilizar o delineamento composto central rotacional na otimização dos parâmetros físicos de pães incorporados de açaí e quitosana. Foram definidas como variáveis independentes: a quantidade açaí em pó e quitosana.Foram incorporadas em níveis variando de 0 a 20 g e 0 a 1,8 g, respectivamente. Através de superfícies de respostas foram avaliados os efeitos sobre as características físicas das massas e pães: fator de expansão máximo, volume produzido e específico, densidade e índice de expansão. De acordo com os resultados obtidos, a densidade apresentou valores abaixo de $0,4 \mathrm{~g} / \mathrm{mL}$, quando a incorporação de açaí em pó foi inferior a $16 \mathrm{~g}$ e quitosana entre 0,6 a $1,4 \mathrm{~g}$, consequentemente, nestas condições, o volume específico foi maximizado, com valores superiores a $3,00 \mathrm{~mL} / \mathrm{g}$. Para o volume produzido, a maximização foi para quantidades de até $0,6 \mathrm{~g}$ de quitosana e até $6 \mathrm{~g}$ de açaí em pó, a partir deste ponto, houve prejuízo nos parâmetros físicos dos pães.
\end{abstract}

\section{INTRODUÇÃO}

O consumo de fibras dietéticas oferece benefícios à saúde, incluindo proteção contra doenças cardiovasculares, tumores, redução do colesterol sanguíneo sérico e também regula os níveis de glicose do sangue (Qiang et al., 2009). A quitosana é um polímero natural produzido a partir da desacetilação da quitina, sendo encontrada em carapaças de crustáceos e insetos, além de parede celular de fungos (Kumar, 2010). Possui atividade antimicrobiana e comportamento semelhante às fibras dietéticas, sendo aplicada em muitas áreas, como biotencologia, produtos biomédicos e tratamento de água (Lafarga et al., 2013).

Dentre os benefícios comprovados do açaí em pó estão a capacidade de reduzir o colesterol, conforme estudo desenvolvido por Souza et al. (2012), onde foi observada a redução dos níveis de colesterol em ratos alimentados com polpa de açaí, resultante do aumento da taxa de excreção biliar e de esteróis, com o aumento da captação de LDL pelo fígado por meio do aumento da regulação do LDL-R. Fragoso et al. (2013) verificaram que o açaí em pó, em proporções de $5 \%$, pode reduzir o desenvolvimento de processos de carcinogênese quimicamente induzido em cólon de ratos wistar. Possui efeito neuroprotetor in vitro, com a inibição da agregação de $\beta$-amilóide, conforme estudo apresentado por Wang et al. (2013).

O estudo tem como objetivo estudar a incorporação de açaí em pó e quitosana através do uso do delineamento composto central rotacional (DCCR) em formulações de pães tipo forma visando à otimização dos parâmetros físicos de expansão dos produtos. 


\section{METODOLOGIA}

\subsection{Delineamento Experimental}

O desenvolvimento das formulações de pães tipo forma foi realizado a partir de uma formulação padrão, adaptada de Gragnani (2010), cuja composição é: 100\% de farinha de trigo; 55-60\% de água, $10 \%$ de Gordura Vegetal Hidrogenada; 5\% de açúcar, 3,3\% de fermento biológico e $2 \%$ de sal.

$\mathrm{Na}$ tabela 1 são apresentados as faixas de valores codificados e reais utilizados para os ensaios e na tabela 2 é apresentada a matriz do planejamento.

Tabela 1 - Variáveis e níveis do planejamento experimental completo $2^{2}$

\begin{tabular}{|c|c|c|c|c|c|}
\hline \multirow[b]{2}{*}{ Variáveis Independentes } & \multicolumn{5}{|c|}{ Níveis codificados e reais das variáveis independentes } \\
\hline & $-\alpha=-1,41$ & -1 & 0 & +1 & $+\alpha=+1,41$ \\
\hline Açaí em pó (g) & 0 & 5 & 10 & 15 & 20 \\
\hline Quitosana (g) & 0 & 0,45 & 0,90 & 1,35 & 1,80 \\
\hline Açaí em pó $(\%) *$ & $0 \%$ & $1,6 \%$ & $3,3 \%$ & $5,0 \%$ & $6,6 \%$ \\
\hline Quitosana (\%)* & $0 \%$ & $0,15 \%$ & $0,3 \%$ & $0,45 \%$ & $0,60 \%$ \\
\hline
\end{tabular}

*Em relação a farinha de trigo (base 100).

Para o desenvolvimento das formulações de pães tipo forma incorporadas com diferentes quantidades de quitosana e açaí em pó foi utilizado o Delineamento Composto Central Rotacional (DCCR). Foi aplicado um planejamento fatorial $2^{2}$ completo, totalizando 11 ensaios, sendo quatro fatoriais (combinação dos níveis -1 e +1$)$, quatro axiais $(-\alpha$ e $+\alpha)$ e três repetições no ponto central (0) para estimativa do erro padrão.

Tabela 2 - Matriz do delineamento experimental com valores codificados e reais

\begin{tabular}{ccccc}
\hline Ensaios & Açaí em pó & Quitosana & Açaí em pó $(\mathbf{g})$ & Quitosana $(\mathbf{g})$ \\
\hline $\mathbf{1}$ & -1 & -1 & 5 & 0,45 \\
$\mathbf{2}$ & +1 & -1 & 10 & 0,45 \\
$\mathbf{3}$ & -1 & +1 & 5 & 1,35 \\
$\mathbf{4}$ & +1 & +1 & 10 & 1,35 \\
$\mathbf{5}$ & $-1,41$ & 0 & 0 & 0,90 \\
$\mathbf{6}$ & $+1,41$ & 0 & 20 & 0,90 \\
$\mathbf{7}$ & 0 & $-1,41$ & 10 & 0 \\
$\mathbf{8}$ & 0 & $+1,41$ & 10 & 1,80 \\
$\mathbf{9}$ & 0 & 0 & 10 & 0,90 \\
$\mathbf{1 0}$ & 0 & 0 & 10 & 0,90 \\
$\mathbf{1 1}$ & 0 & 0 & 10 & 0,90 \\
\hline
\end{tabular}

\subsection{Processamento dos Pães Tipo Forma}

Os ingredientes foram pesados em balança semi-analítica separadamente. Aplicou-se o método direto, onde todos os ingredientes são colocados simlutaneamente no início da etapa de mistura, com exceção do sal e água. Eles foram misturados em misturadora de escala semi- 
industrial durante 1 minuto em baixa velocidade para a homogeneização dos ingredientes, em seguida foi adicionada a água e misturada por 3 minutos em velocidade média, por último foi adicionado o sal e a massa foi misturada em alta velocidade por 6 minutos até o seu completo desenvolvimento. As massas foram divididas em porções de $250 \mathrm{~g}$ e moldadas na forma de elipses manualmente. Foram colocadas em fôrmas de folha galvanizada de ferro de chapa única para pão de forma sem tampa. Em seguida, colocadas em câmara de fermentação regulada a temperatura de $28{ }^{\circ} \mathrm{C} \pm 2{ }^{\circ} \mathrm{C}$ e $80 \%$ de umidade relativa, durante uma hora e trinta minutos. Ao final da fermentação, as massas foram assadas sem vapor durante 20 minutos a temperatura de $220^{\circ} \mathrm{C}$ em forno elétrico de lastro Continental Advance Turbo®. Os pães foram resfriados durante uma hora em temperatura ambiente.

\subsection{Avaliação Física das Massas e dos Pães Tipo Forma}

Avaliação do processo de fermentação pela técnica de perfil livre de expansão: A expansão das massas durante o processo de fermentação foi avaliada através do procedimento experimental de Perfil Livre de Expansão desenvolvido por Gabric et al. (2011), com modificações, onde as massas foram consideradas como elipses truncadas, conforme ilustra a figura 1, foram medidas, a cada 10 minutos, as dimensões com o auxílio de régua milimetrada simples. As massas foram colocadas em fôrmas de alumínio com dimensões de $30 \mathrm{~cm}$ x 30 $\mathrm{cm}$ para permitir a sua livre expansão sem restrições dimensionais.

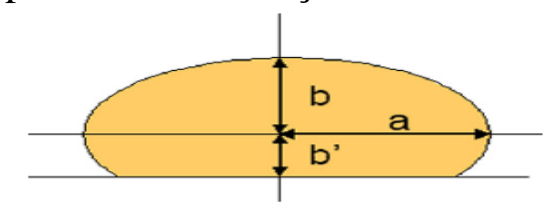

Figura 1 -Parâmetros de elipse truncada

O volume das massas para cada tempo de medição foi calculado com base na fórmula da elipse e sua rotação em torno do eixo y, conforme demonstra a equação 2 .

$V\left(c m^{3}\right)=\pi a^{2}\left(\frac{2 b}{3}+b^{\prime}-\frac{b^{3}}{3 b^{2}}\right)$

Onde: $\mathrm{a}=$ largura da elipse $(\mathrm{cm}) ; \mathrm{b}=$ altura da elipse - do centro a elipse superior $(\mathrm{cm})$; $b^{\prime}=$ altura da elipse - do centro para a parte inferior $(\mathrm{cm})$.

O fator de expansão do volume $\left(\mathrm{cm}^{3}\right)$ - VEF, foi calculado através da equação 3 .

$V E F=\frac{V-V_{o}}{V_{o}}$

Onde: $\mathrm{V}=$ Volume da massa ao longo do tempo de fermentação $\left(\mathrm{cm}^{3}\right) ; \mathrm{V}_{\mathrm{o}}=$ Volume incial da massa $\left(\mathrm{cm}^{3}\right)$.

Volume Produzido: Porções de massa de $15 \mathrm{~g}$, foram colocadas em provetas de $100 \mathrm{~mL}$ previamente esterilizadas para medição dos volumes das massas durante o processo de fermentação. Para o cálculo do volume produzido $(\Delta \mathrm{V})$ utilizou-se a subtração entre o volume final produzido, após uma hora e trinta minutos de fermentação e o volume inicial das massas na provetas, os resultados expressos em $\mathrm{mL}$. 
Volume Específico: As massas dos pães foram determinadas em balança semi-analítica e expressa em gramas. $\mathrm{O}$ volume deslocado dos pães foi medido através de preenchimento de recipiente plástico e transparente com semente de painço expressando o resultado $\mathrm{mL}$. $\mathrm{O}$ volume específico foi calculado pela divisão do volume deslocado do pão $(\mathrm{mL})$ pela sua massa (g), segundo método $\mathrm{n}^{\circ}$ 72-10 da AACC (1995).

Densidade: A densidade foi calculada através da relação inversa entre o volume deslocado e o peso da amostra assada.

Índice de Expansão: Para o cálculo do índice de expansão foi adaptada a medotologia utilizada por Silva et al. (2003) para pães de queijo. As massas foram moldadas na forma esférica para permitir as medições do diâmetro e da altura. com auxílio de régua milimetrada simples. O Índice de Expansão (IE) dos pães foi calculado através da equação 4:

Índice de Expansão $(I E)=\frac{\frac{\left(D_{p}+H_{p}\right)}{2}}{\frac{\left(D_{m}+H_{m}\right)}{2}}$

Onde: $\mathrm{D}_{\mathrm{p}}$ e $\mathrm{H}_{\mathrm{p}}=$ Diâmetro e altura dos pães após o forneamento $(\mathrm{cm}) ; \mathrm{D}_{\mathrm{m}}$ e $\mathrm{H}_{\mathrm{m}}=$ Diâmetro e altura das massas moldadas $(\mathrm{cm})$.

\subsection{Análise Estatística}

A avaliação dos resultados dos parâmetros físicos no desenvolvimento das formulações através do delineamento composto central rotacional foi realizada por superfície de resposta e suas respectivas curvas de contorno após a análise de variância (ANOVA) e regressão, foi realizado teste de médias ao nível de $5 \%$ de significância. A análise foi realizada no programa STATISTICA 7.0.

\section{RESULTADOS E DISCUSSÃO}

A tabela 3 apresenta os valores obtidos para os parâmetros físicos dos pães tipo forma.

Tabela 3 - Parâmetros físicos dos pães tipo forma

\begin{tabular}{|c|c|c|c|c|c|c|c|}
\hline Ensaios $^{1}$ & $\begin{array}{c}\text { Açaí } \\
\text { (g) }\end{array}$ & $\begin{array}{c}\text { Quitosana } \\
\text { (g) }\end{array}$ & $\begin{array}{c}\text { Volume } \\
\text { Específico } \\
(\mathrm{mL} / \mathrm{g})\end{array}$ & $\begin{array}{c}\text { Densidade } \\
(\mathrm{g} / \mathrm{mL})\end{array}$ & $\begin{array}{l}\text { Índice de } \\
\text { Expansão }\end{array}$ & $\begin{array}{c}\text { Volume } \\
\text { Produzido } \\
(\mathrm{mL})\end{array}$ & $\begin{array}{c}\text { Fator de } \\
\text { expansão } \\
\left(\mathrm{cm}^{3}\right)\end{array}$ \\
\hline E01 & 5 & 0,45 & $3,52^{\mathrm{a}} \pm 0,02$ & $0,27^{\mathrm{d}} \pm 0,01$ & $1,29^{\mathrm{a}} \pm 0,01$ & $18,33^{\mathrm{a}} \pm 0,32$ & $2,11^{\mathrm{a}} \pm 0,03$ \\
\hline E02 & 10 & & $2,94^{\mathrm{e}} \pm 0,02$ & $0,37^{\mathrm{b}} \pm 0,01$ & $1,20^{\mathrm{c}} \pm 0,01$ & $12,66^{\mathrm{c}} \pm 0,28$ & $1,93 \pm 0,01$ \\
\hline E03 & 5 & 1,35 & $3,12^{\mathrm{d}} \pm 0,01$ & $0,30^{c} \pm 0,02$ & $1,27^{\mathrm{a}} \pm 0,01$ & $16,00^{\mathrm{b}} \pm 0,57$ & $2,03^{\mathrm{b}} \pm 0,02$ \\
\hline E04 & 10 & 1,35 & $2,63^{\mathrm{f}} \pm 0,01$ & $0,34^{\mathrm{c}} \pm 0,01$ & $1,12^{\mathrm{d}} \pm 0,01$ & $10,34^{\mathrm{d}} \pm 0,42$ & $1,80^{\mathrm{cd}} \pm 0,02$ \\
\hline E05 & 0 & 0,90 & $3,13^{\mathrm{d}} \pm 0,01$ & $0,30^{\mathrm{c}} \pm 0,02$ & $1,21^{\mathrm{b}} \pm 0,02$ & $16,03^{\mathrm{b}} \pm 0,31$ & $2,03^{\mathrm{b}} \pm 0,02$ \\
\hline E06 & 20 & 0,90 & $2,17^{\mathrm{c}} \pm 0,01$ & $0,44^{\mathrm{a}} \pm 0,03$ & $1,12^{\mathrm{d}} \pm 0,01$ & $12,67^{\mathrm{c}} \pm 0,19$ & $1,60^{\mathrm{d}} \pm 0,04$ \\
\hline E07 & 10 & 0 & $2,91^{\mathrm{e}} \pm 0,02$ & $0,37^{\mathrm{b}} \pm 0,01$ & $1,21^{\mathrm{b}} \pm 0,01$ & $11,05^{\mathrm{d}} \pm 0,21$ & $1,94^{\mathrm{c}} \pm 0,05$ \\
\hline E08 & 10 & 1,80 & $2,37^{\mathrm{b}} \pm 0,01$ & $0,40^{\mathrm{a}} \pm 0,02$ & $1,19^{\mathrm{c}} \pm 0,03$ & $12,66^{\mathrm{c}} \pm 0,33$ & $1,70^{\mathrm{d}} \pm 0,01$ \\
\hline E09 & 10 & 0,90 & $2,58^{\mathrm{f}} \pm 0,01$ & $0,38^{\mathrm{b}} \pm 0,02$ & $1,18^{\mathrm{c}} \pm 0,01$ & $12,57^{\mathrm{c}} \pm 0,32$ & $1,71^{\mathrm{d}} \pm 0,04$ \\
\hline E10 & 10 & 0,90 & $2,58^{\mathrm{f}} \pm 0,02$ & $0,39^{\mathrm{b}} \pm 0,02$ & $1,18^{\mathrm{c}} \pm 0,01$ & $12,69^{\mathrm{c}} \pm 0,31$ & $1,69^{\mathrm{d}} \pm 0,05$ \\
\hline E11 & 10 & 0,90 & $2,57^{\mathrm{f}} \pm 0,01$ & $0,38^{\mathrm{b}} \pm 0,01$ & $1,18^{\mathrm{c}} \pm 0,01$ & $13,04^{\mathrm{c}} \pm 0,39$ & $1,69^{\mathrm{d}} \pm 0,04$ \\
\hline
\end{tabular}

${ }^{1}$ Letras distintas em uma mesma coluna apresentaram diferenças significativas ao nível de $5 \%$ de significância $(\mathrm{p} \leq 0,05)$ 
Os ensaios correspondentes aos pontos centrais (9 a 11) não apresentaram diferença significativa entre si, ao nível de $5 \%$ de significância, dentre os parâmetros de volume específico e produzido, densidade, índice de expansão e fator de expansão. O volume específico variou de $3,52 \mathrm{~mL} / \mathrm{g}$ a $2,17 \mathrm{~mL} / \mathrm{g}$ quando a incorporação de açaí em pó foi máxima, $20 \mathrm{~g}$, o que ocasionou o maior valor de densidade obtido, de $0,44 \mathrm{~g} / \mathrm{mL}$, para o ensaio 6 , que também obteve o menor índice de expansão dentre todos os ensaios realizados, com 1,12; juntamente com o ensaio 4, este, por sua vez, apresentou o menor volume produzido de massa, com 10,34 mL, não apresentando diferença significativa do ensaio 7, com 11,05 mL. Já para o fator de expansão máximo das massas, o ensaio 6 apresentou o menor valor, com $1,60 \mathrm{~cm}^{3}$.

O ensaio 1, adicionado de $5 \mathrm{~g}$ de açaí em pó e $0,45 \mathrm{~g}$ de quitosana apresentou o maior valor de volume específico $(3,52 \mathrm{~mL} / \mathrm{g})$, como consequência, obteve o menor valor de densidade $(0,27 \mathrm{~g} / \mathrm{mL})$, maior índice de expansão $(1,29)$, volume produzido com $18,33 \mathrm{~mL}$ e fator de expansão máximo das massas, obtendo $2,11 \mathrm{~cm}^{3}$. Apenas para o índice de expansão, o ensaio 1 não diferiu estatisticamente dos demais ensaios.

A figura 2 apresenta a superfície de resposta e a curva de contorno da ação do açaí em pó e da quitosana sobre o fator de expansão máximo das massas.
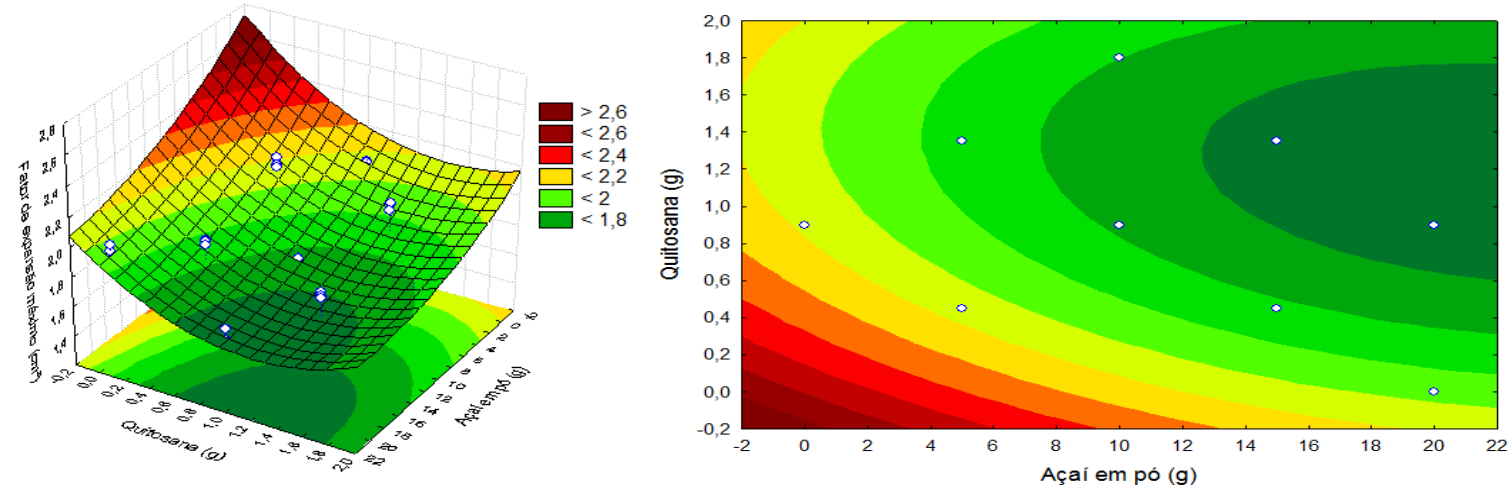

Figura 2 - Superfície de resposta, curva de contorno da ação do açaí em pó e quitosana sobre o fator de expansão máximo da massas

O fator de expansão máximo das massas variou de $1,60 \mathrm{~cm}^{3}$ (ensaio 5) a 2,11 cm (ensaio 1). De acordo com a superfície de resposta gerada, a região otimizada consistitiu para valores superiores a 2,00 $\mathrm{cm}^{3}$, compreendendo as quantidades de até $1,2 \mathrm{~g}$ de quitosana e $7 \mathrm{~g}$ de açaí em pó, a incorporação deste, foi mais prejudicial ao fator de expansão. A região de menor fator de expansão foi obtida para valores inferiores a $1,80 \mathrm{~cm}^{3}$, com quantidades superiores a $0,8 \mathrm{~g}$ de quitosana, quando combinada com quantidade superior a $15 \mathrm{~g}$ de açaí em pó.

A produção de gás carbônico durante a fermentação relaciona-se com o fator de expansão das massas, tendo em vista que a retenção deste gás na matriz protéica do glúten é o responsável por esta expansão, quanto maior a quantidade de gás produzida, maior será o fator de expansão. Quando há danos, fissuras ou ruptura do glúten, devido à incorporação de ingredientes não-formadores de glúten, como é o caso do açaí em pó e quitosana, o fator de expansão máximo sofre redução em seu valor. 
A figura 3 apresenta a superfície de resposta e curva de contorno da ação do açaí em pó e quitosana sobre o volume produzido das massas.
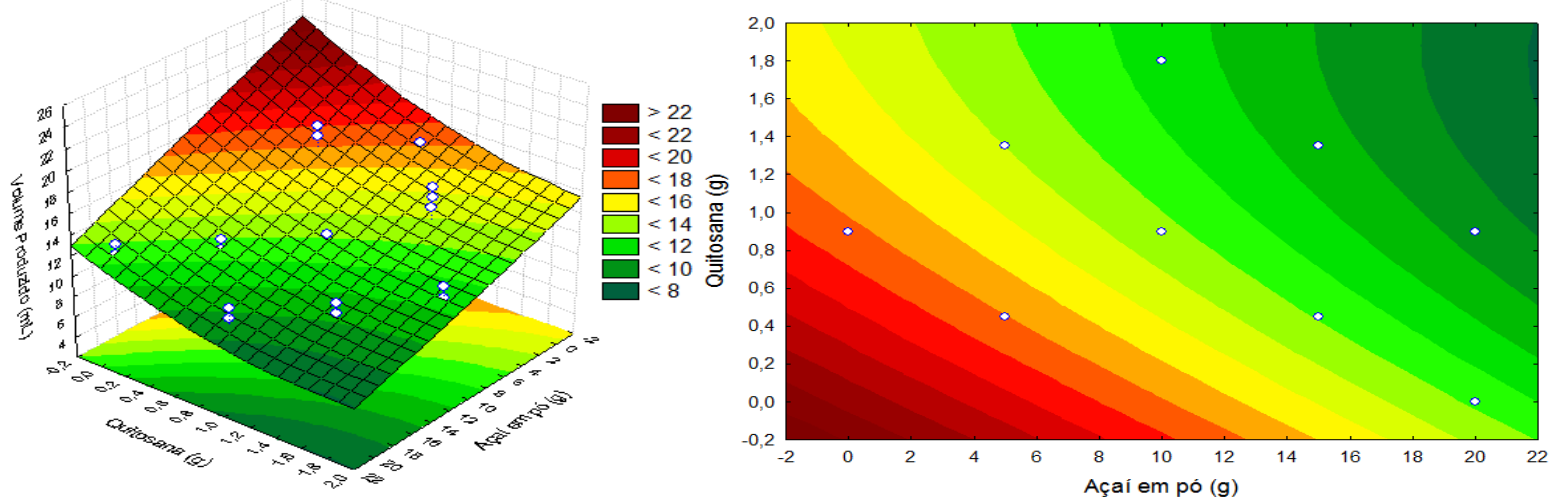

Figura 3 - Superfície de resposta, curva de contorno da ação do açaí em pó e quitosana sobre o volume produzido das massas

Observa-se que a máxima quantidade de volume produzido ocorreu para valores de até $0,8 \mathrm{~g}$ de quitosana incorporada e $8 \mathrm{~g}$ de açaí em pó. Para quantidades superiores a $14 \mathrm{~g}$ de açaí em pó na presença de quitosana, o volume produzido decresceu para valores menores que $16 \mathrm{~mL}$, reduzindo a capacidade de expansão das massas.

A figura 4 fornece a superfície de resposta e curva de contorno da ação do açaí em pó e quitosana no volume específico dos pães.
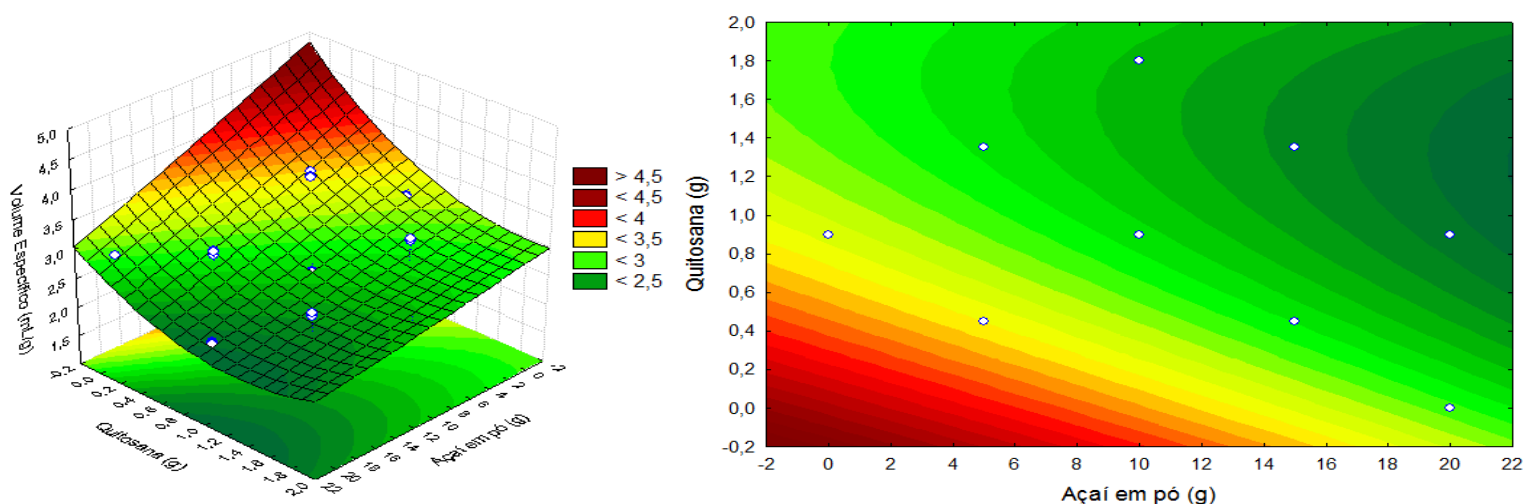

Figura 4 - Superfície de resposta, curva de contorno da ação do açaí em pó e quitosana sobre o volume específico dos pães

De acordo com Capriles (2011), o volume específico é uma importante propriedade física dos pães, uma vez que exerce forte influência na preferência do consumidor. O volume específico foi inferior a $3,5 \mathrm{~mL} / \mathrm{g}$ quando a incorporação de quitosana foi superior a $0,8 \mathrm{~g}$; o efeito do açaí em pó foi prejudicial para quantidades acima de $8 \mathrm{~g}$, a região de mínimo apresentada foi correspondente à quantidades maiores que $1,2 \mathrm{~g}$ de quitosana e de $20 \mathrm{~g}$ de açaí em pó.

A figura 5 apresenta a superfície de resposta e a curva de contorno da ação do açaí em pó e quitosana sobre a densidade dos pães tipo forma. 

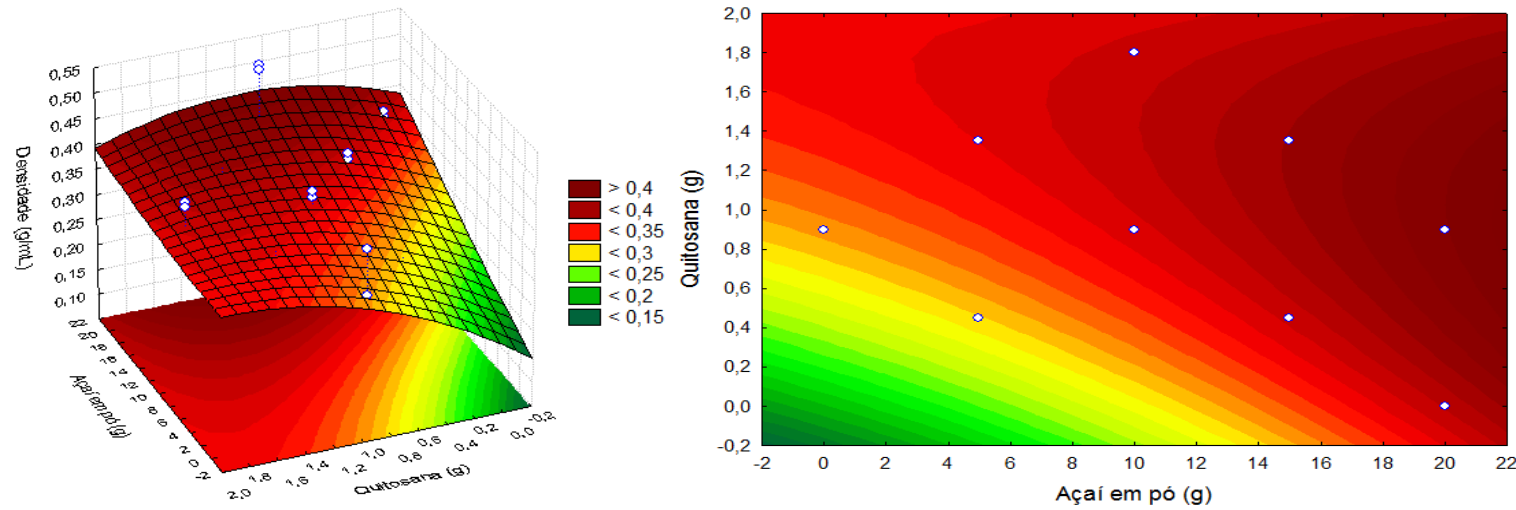

Figura 5 - Superfície de resposta, curva de contorno da ação do açaí em pó e quitosana sobre a densidade dos pães

A região ótima para a variável resposta densidade compreendeu para valores inferiores a faixa de 0,2 a $0,3 \mathrm{~g} / \mathrm{mL}$, onde apresentou adição de quitosana de até $0,8 \mathrm{~g}$ e até $8 \mathrm{~g}$ de açaí em pó. Quantidades superiores a $14 \mathrm{~g}$ de açaí em pó, sem a adição de quitosana, prejudicou a densidade dos pães, a elevando, produzindo produtos de qualidade inferior. Os valores variaram de $0,27 \mathrm{~g} / \mathrm{mL}$ para o ensaio 1, incorporado com $0,45 \mathrm{~g}$ de quitosana e $5 \mathrm{~g}$ de açaí em pó a $0,44 \mathrm{~g} / \mathrm{mL}$ com $0,90 \mathrm{~g}$ de quitosana e $20 \mathrm{~g}$ de açaí em pó.

A figura 6 fornece a superfície de resposta e curva de contorno da ação do açaí em pó e quitosana sobre o índice de expansão dos pães.
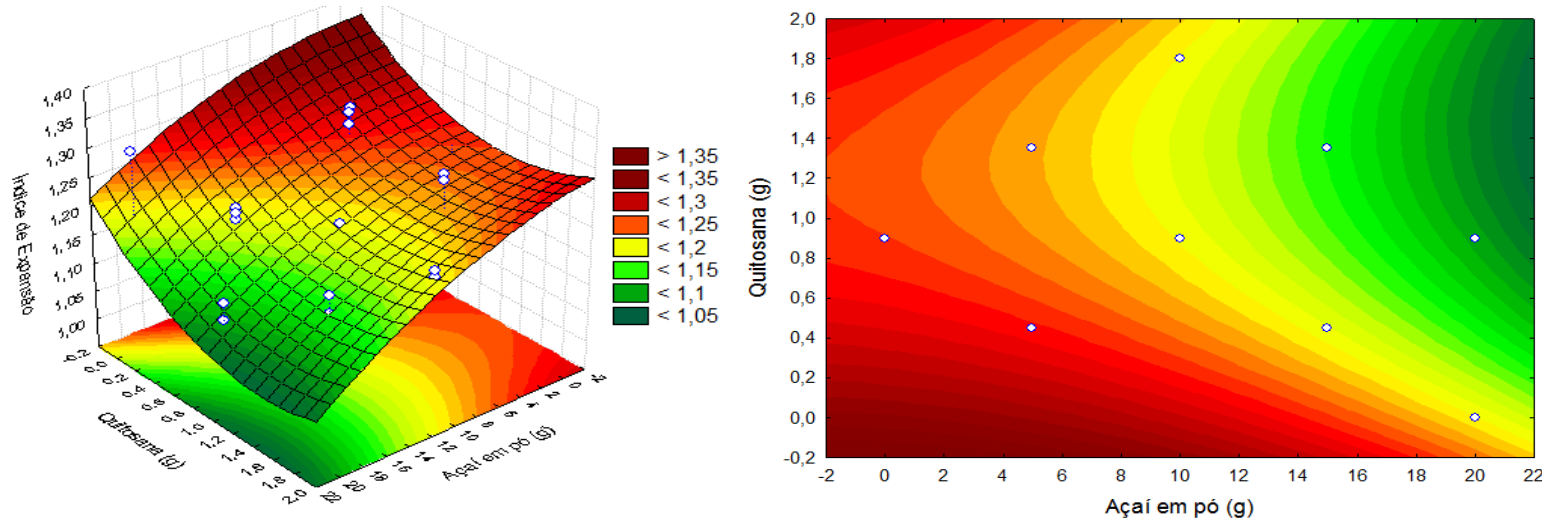

Figura 6 - Superfície de resposta, curva de contorno e modelo matemático da ação do açaí em pó e quitosana sobre o índice de expansão dos pães

O índice de expansão apresentou valores superiores a 1,30 quando a adição de quitosana foi de até $0,5 \mathrm{~g}$, quando combinada com quantidades de até $6 \mathrm{~g}$ de açaí em pó. Amaya et al., (2013) estudaram o índice de expansão de pães tipo forma incorporados com suco de manga, obtendo resultados de 1,15 e 1,02 para formulações adicionadas de 50 e $100 \%$ de suco em substituição à água, valores inferiores aos obtidos neste estudo, o que mostra que o açaí em pó e a quitosana proporcionaram menores danos à qualidade dos pães.

\section{CONCLUSÃO}

Diante dos resultados obtidos, pôde-se concluir que A incorporação de quitosana e açaí em pó, por não serem formadores de glúten, reduz à qualidade física de pães tipo forma em 
quantidades superiores a $0,8 \mathrm{~g}$ e $6 \mathrm{~g}$, respectivamente, o que pode melhorar o valor nutricional destes produtos sem prejuízos à sua qualidade final.

\section{REFERENCIAS}

AMAYA, D. A. D.; PINHEIRO, G. K.; BRASIL, D. L.; MELO, P. E. F.; ZAMBELLI, R. A. Incorporação de suco de manga em formulações de pães tipo forma: avaliação das características físicas. Magistra, v. 25, n. 1, p. 436-440, 2013.

AMERICAN ASSOCIATION OF CEREAL CHEMISTS - A. A. C. C. Approved methods of American Association of Cereal Chemists. 9 ed. St. Paul: 1999.

CAPRILES, V. D.; AREAS, J. A. G. Avanços na produção de pães sem glúten: aspectos tecnológicos e nutricionais. Bol. CEPPA, v. 29, n. 1, p. 15-21, 2011.

FRAGOSO, M. F.; ROMUALDO, G. R.; RIBIERO, D. A.; BARBISA, L. F. Açai (Euterpe oleracea Mart.) feeding attenuates dimethylhydrazine-in-duced rat colon carcinogenesis. Food and Chem. Toxic., v. 58, n. 1, p. 68-76, 2012.

GABRIC, D.; BEN-AISSA, F.; LE-BAIL, A.; MONTEAU, J. Y.; CURIC, D. Impact of process conditions on the structure of pre-fermented frozen dough. J. Food Eng. n.105, p. 361-366, 2011.

KUMAR, C. G.; MAMIDYALA, S. K.; SRIDHAR, B. D. B.; DEVI, G. S.; KARUNA, M. S. Syn-thesis of biosurfactant-based silver nanoparticles with purified rhamnolipidsisolated from pseudomonas aeruginosa BS-161R, J. Microbiol. Biotechnol, v. 20, p. 1061-1068, 2010.

LAFARGA, T.; GALLAGHER, E.; WALSH, D.; VALVER, J.; HAYES, M. Chitosancontainingbread made using marine shellfishery byproducts: functional, bioactive, andquality assessment of the end product, J. Agric. Food Chem, v. 61, p. 8790-8796, 2013.

SILVA, M. R.; GARCIA, G. K. S.; FERREIRA, H. F. Caracterização química, física e avaliação da aceitação de pão de queijo com baixo teor energético. Alim. e Nutr, v. 14, n. 1, p. 69-75, 2003.

SOUZA, M. O.; SILVA, L. S.; MAGALHÃES, C. L. B.; FIGUEIREDO, B. B.; COSTA, D. C.; SILVA, M. E.; PEDROSA, M. L. The hypocholesterolemic activity of açaí (Euterpeoleracea Mart.) is mediated by the enhanced expression of the ATP-binding cassette, subfamily G transporters 5 and 8 and low-density lipoprotein receptor genes in the rat. Nutr. Res., v. 32, n. 1, p. 976-984, 2012.

QIANG, X.; YOUNGLIE, C.; QIANBING, W. Health benefit application of functional oligosaccharides. Carbohyd. Polym, v. 77, n. 3, p. 435-441, 2009.

WANG, D. Y. S.; MUSGRAVE, I. F.; HARVEY, B. S.; SMID, S. D. Açaí (Euterpe oleraceae Mart.) berry extract exerts neuroprotective effects against $\beta$-amyloid exposure in vitro. Neurosci. Lett., v. 556, n. 3, p. 221-226, 2013. 